\title{
The Meaning of the Matrix: Towards a Cybernetic Critical Theory of Capitalism
}

\begin{abstract}
Shay Hershkovitz
Received: November 28, 2017 Accepted: December 26, 2017 Published: April 5, 2018

doi:10.5296/iss.v6i1.12953ＵRL: http://dx.doi.org/10.5296/iss. v6i1.12953

Abstract

Marxist criticism is most discernible; despite the oft-repeated claim that it is now irrelevant, belonging to an age now past. This essay assumes that criticism originating in the Marxist school of thought continue to be relevant also in this present time; though it may need to be further developed and improved by integrating newer critical approaches into the classic Marxist discourse. This essay therefore integrates basic Marxist ideas with key concepts from 'social systems theory'; especially the theory of the German sociologist Niklas Luhmann's. In this light, capitalism is conceptualized here as a 'super (social) system': a meaning-creating social entity, in which social actors, behaviors and structures are realized. This theoretical concept and terminology emphasizes the social construction of control and stability, when discussing the operational logic of capitalism.
\end{abstract}

Keywords: Social systems, second order cybernetics, constructivism, luhmann, social construction, capitalism, post-marxism, autopoiesis 


\section{Introduction}

It is doubtful whether modern history has had many such all-encompassing, influential, though bitterly contested, phenomena as the one known as capitalism. From amongst the myriad criticisms aimed at this phenomenon, the voice of Marxist criticism is most discernible; despite the oft-repeated claim that it is now irrelevant, belonging to an age now past. This essay assumes that criticism originating in the Marxist school of thought continues to be relevant also in this present time; though it may need to be further developed and improved by integrating newer critical approaches into the classic Marxist discourse.

One of the ways it can be done is by integrating basic Marxist ideas with key concepts from 'social systems theory'; especially the theory of the German sociologist Niklas Luhmann's. In this light, capitalism will be conceptualized here as a 'super (social) system': a meaning-creating social entity, in which social actors, behaviors and structures are realized. This theoretical concept and terminology emphasizes the social construction of control and stability, when discussing the operational logic of capitalism.

It is worth mentioning, that the term 'system', in the context of capitalism, is not estranged from the Marxist critical tradition. Yet, a refinement of this critical perspective, mostly via the integration into it of concepts belonging to the philosophical school known as Second-Order Cybernetics and its various derivatives from Constructivism and system theory, will allow us to begin constructing a new theoretical-critical framework. It sheds a fresh light on the critique of capitalism and offers an original terminological frame within which to discuss this phenomenon. All this is done while maintaining the basic kinship with Marxian theory and its critique of contemporary capitalism. This theoretical structure is another layer in what is today termed as 'post-marxism': a discourse that strives to relinquish the essentialist precedence the working class had in the Marxist tradition, and to abandon the notion of history evolving towards its supreme purpose; while at the same time further develop some of the traditional Marxian insights (Laclau \& Mouffe, 1987; Sim, 2011).

First, I shall present few key concepts from social system theory - upon which the description of the capitalist super-system will be later constituted. Second, I shall present a general outline of a critical systemic theory of capitalism, with emphasis on the operational logic of what will be referred to as the capitalist super-system.

\section{Social Systems Theory: General Outline}

The scope and frame of this article permits us only a limited presentation of the constructivist approach and the many incarnations of the social systems theory (Note 1). Included within the spectrum of approaches classified as 'constructivist', are system theory, second-order cybernetics, autopoiesis (the biological theory of consciousness) and the sociological theory of Niklas Luhmann.

A 'system' is a combination of different components operating within a certain environment. Each component has its own traits and functions; yet, their interaction has an effect upon the whole complex; and they work together under a common goal. This goal is what predefines the total achievement to which the actions of the system are aspiring; it is also what regulates 
and organizes the relations between the various components, as well as the sum of the system's relation with its surroundings. Between the components of the systems - themselves comprised of sub-elements - exists an inherent tension, linking the system's action towards that which they are aimed, and their independent goals. This tension, when reflects a similarity between the system goal and the aims of the components actions, is what allows an operationalization of the system's goal with the practical actions leading to its achievement (Von Bartalanffy, 1968).

The systems here under discussion are autopoietic; i.e., they manufacture themselves and their components, while defining themselves as entities in a demarcated surrounding. In this sense, utilizing Maturana and Varela's, Luhmann's and Von Foerster's discourse, the social system is an 'interpretative' system, observing and 'discussing' its surroundings, that is, creating for itself meanings regarding events (or 'resonance' created by events) in its environment (Luhmann,, 1982, 1995; Maturana \& Varela, 1979, 1988; Von Foerster, 1974, 1981, 2003). The social system's interpretation of its surrounding, or the significance it attributes to events - are what shape the system itself in an autopoietic process. The interpretative or significance-awarding process is based upon this shaping process. Moreover, the system is defined by events in its vicinity, in turn molding its environment and so on in a continuous cycle (Luhmann, 1995). In other words, the process of interoperation and the creation of meanings are both the input and the output of the system; it is both what the system produces and what it is consumes.

A key element here is therefore the notion of the social system as an 'observing system' or a communicative system - this is a very different idea the than more common concept in social science which tends to identify social system as a 'collection of people'. The way in which we examine social systems tends to view them as communicative, meaning - instilling systems; 'observing-interpreting' systems- which fashion, through observation, concrete meanings. These meanings are ultimately translated into structures, agents, behaviors, beliefs, symbols and so on. They are themselves the grounds upon which the process of observation takes place. Yet, it is worthwhile to keep in mind the distinction between what we refer to as system and what we would refer to as foundation upon which a system exists. The latter is not part of what is referred to as the structure of the system. Luhmann's theoretical framework does not include human beings as a part of the social systems. He sees these systems only as a system of communications, with individuals existing beside it and apart from it. (King \& Thornhill, 2005). The fact that we are analyzing the structure of the system and not the individuals, institutions and artifacts comprising it, does not render their place obsolete, nor negate their relevance for social systems.

The autopoeitic principle is linked to the notion of 'operational closure'. Maturana and Varela $(1979,1998)$ use this term to explain how the internal structure of the system is, in fact, a network of active components. In such a complex network, any change in these internal relationships, or any change in the operation of one component (changes that can be caused by an event or an element in the environment), will further cause a change in the relationships and/or operations of the components or the system as a whole. Luhmann further elaborated this idea and claimed that the system does not communicate with the environment, but 
communicates with regard to it. Events in the system's environment are not relevant for the system, unless they create a resonance - from the system's perspective; thus becoming subjects of the system's communication. The idea of operational closure is therefore being used by Luhmann in order to claim that the nature and formation of the social system is determined by itself, and not by inputs from the environment.

The modern social system is characterized by 'functional-differentiation' (Luhmann, 1982). A system which operates in a highly complex environment, must - in order to deal with such complexity - adjust its internal variety to the surroundings. This is achieved by creating a growing number of internally differentiated sub-systems. Functional differentiation means that no one sub-system can control or replace another; and that each one of them fulfils a certain function. Yet, a sub-system will be able to further distinguish itself from the other sub-systems and further create additional sub-systems. At the same time those sub-systems become increasingly interdependent; as they depend upon the existence of the other sub-systems.

Another key concept is that of the 'binary code', coined by Luhmann (1995): this principle states that any system and sub-system puts into play a unique binary code which represents certain values for itself. This code represents the most basic directionality and guiding principles of the system, without which the whole process of self-reference would be unable to form itself. The code is that which enables the process of interpretation or signification Based upon its primary assumptions, all later distinctions are then made. In other words, the system's observations, or the process of meaning-creation which regulates the actions of the system are all based upon the original directives of the binary code. The code itself represents a specific categorization of the system, and it requires means and actions in order to attribute events to those classifications. This differentiation and classification is what permits the means and the actions to be changeable, while the code itself is not.

\section{Outlines of the Capitalist Super-System}

This choice of the concept of 'system' as the basis for a discussion of the social phenomenon known as capitalism is not an obvious one. It is true that a discourse which could be termed 'system-oriented' did and still does take place within the Marxist critique (in its many forms). It is also true that the Marxist discussion of this social phenomenon tends to center on, amongst other things, structural dimensions - particularly when dealing with the facets of coercion and social control of capitalism. In some cases, distinct Marxists, and with Marxist tendencies, presented a 'system' wholeness, or even made explicit use of the term 'system' in the context of the capitalism of their times (e.g. Braudel, 2005; Sklair, 1995; Wallerstein, 1974, 2000). Yet, despite the fact that the theoretical framework in this article is heavily influenced by these thinkers, as we shall see, it is much more influenced by the terminology of system-theory and the Luhmannian theory. This makes it possible for a number of themes and phenomena, related to capitalism, to be addressed anew.

Capitalism can be conceptualized as a 'super-system', and certain elements within this super-system can be analysed as social (sub) systems in their own right. What are the characteristics of the social phenomenon known as the capitalistic super-system and its (sub) 
systems; and why is it permissible for us to discuss it as a system, according the terminology outlined here?

Social phenomena within capitalism, and capitalism as a social phenomenon, conform to the first and primary attribute of systems, that is, a certain structural and guiding logic, or systematic directionality and coherence. When using the word 'certain' I am more than just implying the existence of tensions and contradictions within the system itself, in its structure and components as well as in its underlying logic. Yet, at the same time these do not prevent the system from existing, from conserving its 'sense' and from achieving its goals. Moreover, such tensions are inherent to the nature of the system as comprised of elements, each of which has a limited amount of autonomy and independent goals. But it is this very tension when it is compatible with the systems' objective - which makes these objectives a viable goal.

The structural coherence of the system is manifest in three facets. First, the way in which the system is positioned (in the view of the observer and in its view of itself) as distinct from its surroundings. Second, the fashion in which the overlying system's objective is defined and effects the components, thus serving as a general vector for them. Last, the form in which the system is constructed of (sub) systems, or components, each of which has its own goals and objectives, yet all operating under the same system logic.

The capitalist super-system operates within a certain environment, and its reaction to environmental stimuli (resonance) is both the increase in its internal complexity, as well as in the spread of elements in the surroundings that the system identifies as relevant to its operation. In turn, these expanding observations and interpretations enhance the system's influence on its surroundings; or better put, widen what the system perceives as its environment. It is thus that the system seeks to incorporate nearly completely human existence in the current age, helping fashion the entirety of its stratas. This differs from the time of the system's creation when it operated within a much more limited environment and its influence over it was relatively limited (Note 2).

During the existence of the capitalist super-system the environment in which it operates has become progressively more complex. This increasing intricacy has forced the capitalist system to increase its diversity, in order to maintain compatibility with its surroundings. The diversification of the system has brought about a higher rate of sub-system creation within the capitalist system. At the same time, as mentioned above, it also expanded it scope of observation. Thus it broadens its environment until the latter becomes almost congruent with all aspects of human existence.

The Binary Code of the capitalist super-system Profit/Loss. Every observation made by the super system is being directed, interpreted and understood in the light of this code. Every event is being perceived in terms of profit(able) or loss (unprofitable). In terms of its basic goal the super-system strives to maximize profit and minimize loss. It is essential to emphasize, that the binary code of the super-system is not the goal of the super-system; rather, the code is the basic guidance by which the goal is articulated (and later on, operationalized through sets of actions, structures etc.). 


\section{Macrothink}

In order to achieve its goal, and in the light of the certain permanent characteristics of both the super-system and its environment, the super-system applies an 'operational logic'. This term derived from the implementation of system theory in military affairs, a field known as 'operational art' (Naveh, 1997). In the case of the capitalist super-system, its operational logic is the conservation and expansion of its economic, social, political and cultural order. At the basic of this order stand two elements: control and stability. They are necessary in order to sustain the system itself (i.e. to achieve its goal) and to regulate its structures and behaviors in light of its goal. The elements of control and stability are essential because of two basic conditions, which Marx himself identified some 150 years ago (1978/1847). The first is the chaotic and unpredictable nature of the super-system's surroundings. The second is the basic tension between ever-growing production abilities and the limited capacities of consumption (or demand). In order to overcome this tension, the super-system must therefore ensure an ongoing and growing demand for its products. Under these conditions, one can therefore understand the principles of control and stability. They are meant to enable the maximization of profit and minimization of loss. In other words, those principles enable the system to achieve its goal: to augment the chances of obtaining what it strives to achieve, and to reduce the chances of what it wishes to avoid.

The primary structure that enables the realization of the underlying logic and principles of control and stability is what we shall term 'The Capitalist Matrix': a multifaceted structure, a sequence of (sub) systems operating distinctly from one another, but within the capitalist super-system (which, from this perspective, is their environment). This Matrix is essentially the consequence of a long process of operational differentiation, as it is the means by which the super-system manages to maintain control and stability in a complex environment. Those (sub) systems maintain a mutual affinity while at the same time growing more autonomous from each other. As Luhmann describes modern society, I too believe that when we talk about the (sub) systems comprising the capitalist matrix, it is impossible to talk of a one sub-system hierarchically superior to other sub-systems. Their structure is 'flat' in terms of hierarchy. It is here that I differ from many other Marxist thinkers who would award a privileged status to the production, ideology, national group, global region and so on.

Following Sklair (1995), who discusses three dimensions of trans-national practices (economical, political and socio-cultural); I point to three (sub) systems of the capitalist matrix: the cultural, the economic and the political. This description of the layers comprising the capitalist matrix largely rely on the way in which Gramsci (1971/1929) analyzes the hegemonic facet of capitalistic society: It includes not only the mechanisms permitting capitalist control and hegemony, but also other dimensions such as culture and ideology.

Each of these (sub) systems operates according to its specific binary-code; observes and interprets differently events in the environment; has different goals and means to achieve them; and has a unique and distinct autopoietic cycle. Yet, as a whole they operate as components of the capitalist super-system; and their complex common achievement is aimed at serving the super-system's primary goal.

The autopoietic principle, or the idea of self-reference, means that the capitalist super-system 
defines its own 'rules'; and at the same time, those rules shape the system itself (and vice versa). Let us take the dialectics between capitalism and liberalism for example: capitalism could not have developed without liberal values, and at the same the spread of liberal values is deeply related to the increasing effect of capitalism. Of course, this is not only limited to liberal values (a product of the interpretation process), but also to economic and political structures, agents and activities related to liberalism and so on. The meanings embedded in the latter are both the product of the autopoiesis of Capitalism, and the elements that enable this process. The autopoietic creation of meanings is therefore the creation of meaning of each one of the realities that the systems itself creates. As such, from the wide spectrum of possibilities embedded in the social form, the capitalist system creates special meanings which are relevant to the fashion it defines itself.

I should now, perhaps, clarify some of the issues at the heart of the theoretical structure described above. I shall turn to the discussion of the developmental (historic) dimension of the capitalist super-system, from which will be made clear some matters concerning the interaction of the system with its surroundings and the way in which the system manufactures its constitutive and regulative meanings. I shall than expand upon the concept of the logic of control and stability - a discussion which will shed some light upon the term earlier coined: 'The Capitalist Matrix'.

\section{System-Environment and the System's History}

When dealing with contemporary capitalism, it must be described as global capitalism. This capitalism has attributes of a certain kind which are tied in with the phenomenon known as globalization, and which distinguish it from earlier stages in its development. One of the central differentiating points of global capitalism is the changes it has undergone in terms of time and space, compared with previous forms of capitalism (Bauman, 1998, 2000; Castells, 2000; Habermas, 2001; Harvey, 2006). Marx himself pointed to spreading and expansion as generating, replicating and sustaining capitalism, saying that in order to conserve its existence it must constantly expand. Yet, its current form and scope are total, in that it not only encompasses (or, at least, influences) nearly every physical location on earth, but also seeps into every aspect of life, reshaping the social dimensions of existence - and to a large extent the personal dimensions as well (Foucault, 1977, 1982).

Described in 'system' terminology, we would be able to claim that the capitalist super-system's response to growing environmental stimuli can be seen as a double process: an increase in internal complexity, in turn leading to a change in the system's environment itself. This change is mostly a rebalancing of the environment-system relation largely in order to enable the system to preserve its basic logic and achieve its goals. This is the uniqueness of its action within the environment, in comparison to other social systems. The capitalist super system is in fact an 'expansive system'- a system which inherently reacts to stimuli with expansion, growth and an increase in internal complexity. This expansion and growth is realized in two ways: first, the increased subordination OF the meanings of the social and private life to capitalist logic, values, goals etc. Second, the increasing number of dimension about which the super-systems 'discusses' and to which it creates meanings. This is what we 
can refer to as 'the surplus of capitalist meanings'. It is a totality of meanings created by capitalism, embedded deeply in the existence of contemporary social and personal life. Thus, it shapes social structures and behaviors the light of the Capitalism code, goals, and logic - so much so as to create a sort of 'holy universe', mentioned by Weber when discussing the capitalism of his times (Weber, 2002/1920).

A more concrete illustration of this argument requires us to delve deeper into a discussion of the historic developmental dimension of the capitalist super-system. We recall the Weberian claim by which the roots of the capitalist society are to be found in the Protestant puritanical beliefs of $17^{\text {th }}$ century Europe: a set of values allotting a central position to hard work, entrepreneurship and profit (not necessarily aimed at wealth for its own sake, but rather motivated by religious sentiment. Few developments contributed the expansion of capitalism. First, a relative economic prosperity. Second, a rise in production output and the growth of an influential bourgeoisie thanks to demographic growth in Western Europe. Third, tight ties between the bourgeoisie and the national leadership in the protestant states. The way in which the centralized state applied its internal and foreign policies, as well as the spread of colonialism which opened new markets to European traders, allowed the expansion of international trade and the acceleration in the spread of capitalism. These trends caused inurn the collapse of the old social order and the establishment of a new one. This process can be seen as the transfer from a feudal society to an industrialized one; or, as put by Toffler (1980), a move from the first, agricultural, wave to the second, industrial one.

Let us describe this state of affairs using 'system' terminology: The origin of the capitalist super system is not in one founding moment of a big-bang, but rather in the gradual course of the collapse of old social system in the protestant states due to environmental stimuli, with which the system was unable to cope through differentiation or increased complexity, without changing the nature of the system itself. These stimuli (the religious ethos, demographic, economic and political change etc.) created a resonance within the social system, which tried to react by changing its internal structure, but was no longer compatible with the changing conditions of the environment. The old feudal social system thus lost its systemic coherence and collapsed. From within and upon its ruins, was established a different social system, capitalistic in nature; and, just as importantly, with an aspiration for constant expansion, due to its basic dynamics and logics. Now the central social system, primordial in the sense that it is the first to exist in the new social-political-economic conditions, became the capitalist social system.

The difference between the feudal and industrial - capitalist systems was not limited to merely structural dissimilarities, such as the changing of the economic order (the opening of the market, and the reduction in state involvement) and the political and social structures (such as the growth of the middle class); but also involved a change in the social genome. In other words, they are not the same systems, nor continuity from old to new system. The emerging bourgeoisie was forced to adopt values justifying the privileged position of personal gain above other community values. It therefore adopted ideas and values of individualism, universalism, private property, freedom of ideas, trade, and religion and so on. The adoption of these ideas by the bourgeoisie brought about their rapid assimilation into the 
social system, which came to be comprised of individuals born into, and working within, such a cultural-ethical system. This system is essentially the product and enabler of the process of meaning-creation in response to events in the environment - an autopoietic process. It is the dialectics between the creation of meanings and its influence on the structure and behavior of society, and vice-versa. Put differently, the process of creation of meaning, stimulated from the changing environments, brought about a change - not only in institutions, organizations and social structures, but also - and perhaps mainly - in the way in which society perceives itself. This is the result of the way in which individuals and groups are established within the capitalist system. From the point in which the capitalist system had become the dominant system, creating meaning for groups and individuals (as well as the way in which they perceive themselves), became nigh on exclusive element shaping human life.

The historic development of the capitalist 'industrial' system (or the capitalist system of the industrial era) does not end here. One can point to additional significant developments in the history of the system's interaction with its environment, and its influence over the process of internal differentiation and expansion it is experiencing. This development is represented by the appearance of the information-age over the past few decades.

Unlike the dramatic passage from the feudal, or agricultural era to the industrial, the capitalist social system's reaction to the changes brought on by the information-age were not to create a new system to replace the old collapsing one, but to encourage adjustment (differentiation and further expansion) of structure, function, behavior and social values (Note 3). This change can be seen in the transformation of the super-system into a global one. The super-system's globalism is not only in the sense of its influence everywhere (the globe), but also in the sense of totality (i.e. time and space) over aspects human existence (almost) everywhere and (almost) every time (Castells, 2000). The super-system's transformation was not limited only to its mode of operation, but also expressed in the changes of its internal structures and values - which create new meanings allowing it to function in this new environment. The main point here is that those new meanings penetrate almost all layers of human existence; or more precisely, those layers are provided with meanings whose essence is derived from the capitalist logic. As said, this surplus of capitalist meanings, or the subjection of social and personal meanings to capitalist logic, allows the super-system to operate within a complex and chaotic environment.

The passage from the second to the third age was 'smoother' than the earthquake-like passage from the first to the second, as a result of the ongoing sophistication of the capitalist super-system, which has over the past two centuries successfully implemented formidable control mechanisms. This is control that does not manifest in the form of the application of overt external force (such as would be employed by the feudal or church control mechanisms), but rather a control intrinsic to the way in which individuals and groups are formed in capitalist society: a multi-dimensional control which seeps through to all aspects of life, both overtly and covertly. This point brings us to the discussion of the universal objective of the super-system and an expansion on the discussion on the operational logic of 'control' and 'stability'. 


\section{The Operational Logic: Control and Stability}

As mentioned above, the universal objective of the Capitalist Super-System is the maximization of profit and the minimization of loss. This objective is meant to sustain the whole existence of the system; and it is tied in with the binary-code which determines the system's essence - that of profit/loss. It is this objective that is common to all of its components, or (sub) systems. The operational logic which is necessary in order to achieve this aim is composed of two elements: control and stability. This operational logic is the mediation between the abstract level of the super-system goals, perceptions, logic etc. and the concrete level of social structures and actions. In other words, this operational logic is the translation of the abstract to the concrete, or the ideas to structures and to actions.

There is a certain priority to control over stability, since it is control which makes possible obtaining and maintaining stability, or regaining stability once it has been undermined. This, of course, reminds us of Braverman's (1998) emphasis on 'control', while discussing contemporary capitalism. It might also remind us of Ritzer's (2007) 'McDonaldization of society', where he describes control as one of five characteristics of contemporary capitalist logic. Yet, the sense of control presented here is ascribed to the operational logic of capitalism; and does not see it an end for itself. It is therefore important to note that this dimension of control and stability is not the starting point or the primary logic which defines social structures and actions; and similarly it is not to be identified to the binary-code. Rather, it is itself an expression of the binary-code and the basic rationale of the super-system.

Capitalist control is to be understood, not in the common Marxist manner, of a dominating or coercive element positioned outside the social situation or applying its logic to it; but rather in a Foucaultian manner: a control that is the actual fact of the creation of meaning in light of which all strata of the system are constructed and function. The embodiment of capitalist control is the way in which these significances are created, conserved and reformed, and the way in which these then create structures and social behaviors. In this we walk a path which is slightly different to that common to Marxist thought, as the dimension of control and its expressions is not what regulates the structure and the social behavior, but is itself, rather, an expression of the operational rationale of the system, which regulates agents and the existence of social structures.

The Foucaultian argument is relevant to our discussion of the terms of control, because, when dealing with the reality of 'control', Foucault assumes that any social arrangement putting forth some sort of hierarchical positioning is in itself already an expression of a social arrangement, which I shall term 'a second order social arrangement'. Foucault thus explains that any social arrangement is an embodiment or an expression of the practices of power within a certain society (Foucault 1979, 1982). The positioning of one element in a different position from another, also that power praxis itself, is an expression of a second order social arrangement. Thus understanding Foucault may significantly advance our understanding of the issue of control in the way in which we here consider it.

The truly disturbing issue within the subject of control can be clearly identified using a paraphrase on a title of one of Bourdieu's articles: 'But Who Created the 'Creators?' 


\section{Macrothink}

(Bourdieu 1993). Appropriately paraphrased for our intentions, it would read: 'But who created the controllers?'. Through this question is conveyed an implicit criticism of those Marxist approaches who do not provide a satisfying answer to the question of the creation of classes or individuals of privilege in society, or that their answer is a reduction to the material relations in society. In other words, our investigation into the element of control and stability does not content itself with the presentation of the praxis and mechanism of control, the oppressive agents and institutions or the oppressed classes. Rather, it strives to make comprehensible the founding logic of the social situations under global capitalism. It is not sufficient to attempt to classify and describe a certain social situation, but rather it is necessary to understand the second-order social arrangement which establishes these situations. What the discussion of control in the context of the super-system seeks to understand is, therefore, the most fundamental way in which the social dimension both establish and change.

A perception of capitalist 'power' as being in the hands of groups or individuals exercising external influence over society is only part of the picture. Such a perception could, for instance, hold that money-moguls, giant corporations, national capitalistic economies and so on, are the groups employing covert and overt means of coercion, being the ones to have fashioned capitalist reality. Yet these groups are already operating within a certain reality, and though they are replicating it and adding to its form (while enjoying its fruits), they were not the ones who 'invented' it. They operate within a social context, and this context is the manifestation of control itself. Thus the question remains: who created the creators of capitalist reality? How is the second-order social structure established?

The answer to these questions lies within the description of capitalism as a meaning-creating social system. We must first and foremost return to the principle of the binary code of profit/loss. It is this code which characterized the primordial nature of the capitalist system; it is what set the tone for changing nature of the interactions with neighboring systems; and it is in light of this code that institutions and agents within the system were formed. Finally, it is the binary code which patterns the changing internal dynamics of the system itself.

Thus the answer to the question 'but who created the controllers' is to be found in this principle of the binary code: firstly and lastly, the nature of the capitalist super-system is in the distinction between what is classified as profit and that which is classified as loss. The terms profit and loss should be seen in the wider sense, going beyond the purely economic sense: the principle of gain/loss is translated into a sequence of structures and actions simply defined as aimed at maximizing the benefit and minimizing the risk to the capitalist system. The point I wish to stand upon and hone is that in order to comprehend the principle of control and stability, we must bear in mind the principle underlying the formation both of the controllers and the structure permitting their dominion, while conducting a historical (genealogical) investigation of the development of power oriented social arrangements. Control (and stability) is not an issue of its own, of intrinsic worth. Rather, it is a series of actions and structures (a social arrangement) founded by human beings. These same human beings are the product of actions and institutions and so forth. An examination of the element of control therefore compels us to take into account a social arrangement which we have 


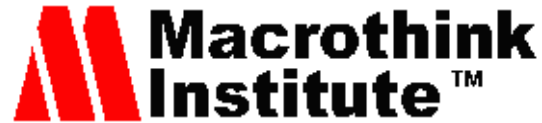

termed of the second order; and this consideration leads us, ultimately, to the principle of the systemic binary code- the principle of gain-profit/loss.

One must not mistake this presentation for a simplistic presentation of the nature of the system, much in the same way as its actions should not be mistaken with random actions, lacking coherent logic: despite this duality, which seems to present us with a very clear distinction between that which is useful to the system and that which is harmful to it, the complex social reality often creates very real tensions in the founding process of the actions enabling the realization of said code. Recognition of the multifaceted nature of social processes is crucial here, as through it we can understand why, despite the supposedly simple principle of a binary code of loss/gain, the capitalist reality does not clearly divide itself between that which is 'good for the system' and that 'which is not good for the system'.

It is important to point out that this description does not reject the status of the subject nor does it subjugate it to a functional explanation, as is often done by system theoreticians on the one hand and Marxist thinkers on the other. That same functionality of the social system is itself a product of human activity. This analysis awards no priority to the activity of the subject or to the existence of social structural functions, but rather sees them as two sides of the same coin existing inseparably from each other. As I have shown, the origin of the binary code of the capitalist super-system is to be found with the (protestant) religious ethos of human beings. This ethos is also connected with a certain social system, yet it was founded by rational, thinking subjects. The nature of the system, the binary code, its genome - all those things upon which and underlying the structures and regulating the behaviors - are all products of human action. It is thus easier to understand the argument here presented regarding the control facet of the system: unlike some central Marxist thinkers, this description does not perceive the controllers as being positioned 'outside' the system, employing practices of coercion; nor would it seem that any class distribution would be 'a law of nature'. Quite the opposite: the privileged classes themselves are a product of those same behaviors generated by the binary code. Put differently- the creators themselves are a product of other creators who are products of other creators etc. Yet it is worth emphasizing that this claim in no way contradicts, or cancels out, the claim that such controllers enjoy the belligerent practices or the social arrangement; this would seem evident. Rather, I believe it impossible to position the privileged group outside the social reality, discussing it as a nearly transcendental entity fashioning 'from without' oppressive social realities - nor would it seem that privileged groups have an essence which distinguishes them qualitatively from the subjugated groups (and note the way in which groups are herein discussed implies the temporary status of the privileged groups, yet another matter revoking any possibility of essentialism within those groups).

Thus we see that capitalist control (and stability) - as a central operational vector of the Super-System - is inherent to the system; it stems from the need of the system to preserve and encourage continuity and expansion in order to sustain it according to the binary code. Control and stability is therefore a sort of systemic 'Deus Ex Machina', a thing imprinted into each of the levels in the most profound way, both explicit and unspecified; without which it would not exist. We cannot discuss it isolated from the capitalist reality as the control and 
stability manifestations are part of this reality, just as it would not be useful to discuss the capitalist super-system without the elements of control and stability. Those elements themselves are part of the way in which actions of individuals and groups are executed, part of the way in which the structures themselves are assembled. Also those classes recognized by the Marxist thinkers as the dominant, oppressive classes, are themselves products of that same capitalist super-system. They operate exactly as they should - being products of the system itself. Yet this is in no way a legitimization, validation, excuse or ethical justification for the oppressive, unjust actions taken through a claim of determinism. It is precisely here that the perception of change as being necessitated from within rather than from without the system comes to bear. The expansion of its horizons done through internal insight rather than caused by an external, impossible reality. Here we again move away from 'revolutionary' approaches which seek to crush the old order and establish a new one instead.

\section{The Capitalist Matrix}

The execution of the super-system's goal and the manifestation of it operational logic is based upon what I refer as the capitalist-matrix. This matrix consists of those (sub)systems which create meanings in social and privet life - that both serve the primary goal of the super-system, and allows the meanings created by the super-system itself to become operational. In this context, these are the principles of control and stability, which are being executed through the capitalist matrix, by the process of meaning-creation. Brevity prevents me from expanding upon each and every component identified within the control system. I shall therefore be content with a general discussion about the essence of the capitalist matrix.

When analyzing a system composed of several sub-systems, we must distinguish between two levels of discussion (and two system types). In the first several sub-layers are positioned distinctly from each other, each one being a functionally united entity, communicatively open and with its own environment. In this sense they are distinct entities with rigid borders in place between them. Yet they are able to interpret their (separate) surroundings and thus adjusting their structure and function to the environmental stimuli. The second layer deals with the tangible dimensions forming the foundation for the existence of these communicative systems - dimensions created and developed in view of the meanings created by these communications. Theses tangible dimensions are the social, economic and political structures within the global capitalist society, and the agents functioning within and from these structures (states, supra-national organizations, corporations, firms, individuals etc.). It is in this layer where we can discuss a fluid, largely chaotic system structure, whose internal borders are hazy and oft-changing (Bauman, 2007; Jameson, 2000; Castelle, 2000). To a great extent it is the fluid and net-shaped structure of this layer which is one of the major attributes of global capitalism, distinguishing it from former, historic incarnations of capitalism.

The capitalist matrix is, then, a multi-dimensional, multi-systemic structure which, when described as a meaning-creating system, exists to us as a closed, significance - generating communicative system. On a more concrete, tangible level it is structured as a composition of structures, agents and behaviors within a certain complex social arrangement. This is a profound, full and multi-dimensional reality shaped by a historical, dynamic process as a 
result of the development of capitalism. It includes the entirety of the dimensions of human existence: from the most abstract perceptual level which include the ways in which we perceive both the world and ourselves compared with it, to the concrete, physical level of social structures and behaviors.

I would like to emphasize three points: first, the capitalist-matrix does not exist in affinity to, or parallel to another, objective reality (as is depicted in the 'Matrix' movie trilogy). Differently put, even where using the term 'capitalist-matrix', I reject outright the Marxist approach which views experienced reality as a false, engineered or manipulated matter faced with a (potentially) objective, exposable reality. In this sense capitalist reality (and all reality) comprises the genuine human experience, one from which there is no opportunity to depart, much as a human being cannot depart from her own body and consciousness. The capitalist-matrix is thus an 'Axiomatic System', in Deleuze and Gattari's (1987) terms - that is, the expansion of axioms, of terms upon an entire plane of reality; a power which operates on beings, which generates transformations and creates both the thought and its subject simultaneously. Second, the Capitalist-Matrix includes aspects of fiction, in the Baudrillardian sense of the word, as expressed in the terms 'Simulacrum' and 'Pastiche'. That is, in a fiction stemming from the loss of the connection to the 'real' essence of things, and the formation of an exclusive affinity to the replicated sign (but not in a discussion stemming from the disconnection from a genuine reality existing and awaiting revelation). (Baudrillard 1983; Jameson 1992).

Lastly, it is a centerless Matrix - with no core or basic division to define it, without any position being privileged, or above any other, without any one system being able to take over or replace any other. In other words, the whole of the systems serves the objectives and follow the basic logic of the super-system; yet every one of them operates within its own domain, has a unique logic and attributes, sometimes existing in conflict and tension with the other sub-systems and the overall systemic logic. In sum, the whole of the systems serves the objective of the super-system and its operational logic: the conservation and expansion of the capitalist control and stability. This logic remains even if every (sub) system has its unique logic and attributes, sometimes existing in conflict and tension with the other sub-systems and the overall systemic logic.

\section{Three (Sub) Systems}

The way in which I approach and analyze the sub-systems of the global capitalist system takes much from Sklair's theory. As mentioned above, he discussed three aspects of trans-national practices (economic, political and socio-cultural) - though mostly touching upon the tangible and abstract aspects of structure, players and behavior. In this sense I am not discussing the same type of systems; rather I am presenting a multi-dimensional structure of social communicative systems which auto-create meanings which are translated into structures, agents and actions. The discussion of those (sub) system (as in general, every systemic discussion), must be conducted in two levels. The first level is of a system which creates meanings by observation and interpretation. The second level is the manner in which those meanings are translated into behaviors of agents and into social structures. It is obvious 


\section{Macrothink}

that those two levels are complementary, and that one cannot exist without the other: the meanings or interpretations of events within the system's environment are meaningless, unless the system applies them, and without being translated into actions, orders and social structures, the latter cannot function without being directed in the light of 'meanings'. In other words, the discussion in the each one of the (sub) systems must refer to the dimensions of 'meaning-creation' and the manner in which they come into being, as well as those actions, agents and structures that shape and are shaped by them, in a recursive process. The (sub) systems which are the base of the capitalist-matrix are as follows:

The cultural (sub)system: mostly realized through the embedding of mechanisms, discourses, world-views, interpretations and social norms, all touching upon the private and collective nature within a world organized according to capitalistic principles (or capitalist meanings). The cultural (sub) system creates meaning which in turn enables control and stability devoid of overt, explicit manifestations, rather operating in a covert, subtle fashion; thus not raising relatively minor objections - hence its efficiency. One of the central expressions of this (sub) system is consumer culture, especially the personal and social significances inherent to any of the aspects of consumption.

The economic (sub)-system: produces communicative acts and interpretations, which create the substance in certain economic orders and regulations (which I will refer to as the principles of capitalist economic). The function of this (sub) system is creating those meanings which eventually will be translated into the various aspects of economic sphere, and will ensure a disciplined (Capitalist) economic order.

The political (sub) system: produces communicative acts and interpretations, which create the substance, meanings and content in political orders, and which translated into institutions and activities which discipline and enforcing certain political order (whom I will refer as democracy and liberalization). Those meanings and its manifestations may be in part non-violent and may be expressed in rules, laws, regulations, political education, practices, institutions and so forth. Yet, at the same time they might be violent and belligerent; as in cases of the use of military power against those who strive to erode under those same meanings (and the political order derived from them).

\section{Conclusion}

I have, throughout this article, presented a critical-theoretical structure used in order to define certain terms regarding contemporary global capitalism; this was done through a discussion of the 'capitalist super structure', its components and the principles regulating its operation. When applied to current situations, this discourse is a challenge to, and a criticism of certain aspects of political, economic, and financial principles - that is, liberalism and capitalism in the age of globalization. It is an interpretive cultural criticism, aimed at a certain (and, in my mind, negative) aspect of these methods, opening up new directions of analytical thinking. However, in no way is this criticism meant to reject or deny recognition of the more positive aspects of the liberal-capitalist system, nor ignore its accomplishments. It is my belief, based upon constructivist philosophical thought, that such an analysis is but one, modest step, of the many needed throughout all aspects of life meant to bring about a change of certain aspects of the 


\section{Macrothink

capitalist reality; making it more just through self-aware, critical analysis.

\section{Reference}

Baudrillard, J. (1983). Simulations. New York: Semiotext(e).

Bauman, Z. (1998). Globalization - the Human Consequences. Cambridge: Polity Press.

Bauman, Z. (2000). Liquid Modernity. Cambridge: Polity Press.

Bourdieu, B. (1999). Structures, Habitus, Practices, in A. Elliott (ed), Contemporary Social Theory. Oxford: Blackwell, 107-118.

Bourdieu, P. (1993/1984). But Who Created the 'creators'. In P. Bourdieu (ed), Sociology in Question. London: Sage, 139 -148.

Braverman, H. (1998). Labor and Monopoly Capital: The Degradation of Work in the Twentieth Century. New-York: Monthly review.

Braudel, F. (2005/1985). The Dynamic of Capitalism. Tel-Aviv: Resling.

Castells, M. (2000). The Rise of the Network Society. Oxford: Blackwell.

Deleuze, J., \& Guattari, F. (1987). Thousand Plateaus: Capitalism and Schizophrenia. Minneapolis: University of Minnesota Press.

Foucault, M. (1977/1975). Discipline and Punish: the Birth of the Prison. New-York: Vintage Books.

Foucault, M. (1982/1971). The Archaeology of Knowledge and the Discourse on Language. New York: Pantheon.

Gramsci, A. (1971/1929-1935). Selections from the Prison Notebooks. London: Lawrence and Wishart.

Habermas, J. (2001). The Postnational Constellation: Political Essays. Massachusetts: MIT.

Harvey, D. (2006). Spaces of Global Capitalism: Towards a Theory of Uneven Geographical Development. London: Verso.

Jameson, F. (1992). Postmodernism, or the Cultural Logic of Late Capitalism. Durham: Duke University Press.

Jameson, F. (2000). Globalization and Political Strategy. New Left Review, 4(4),49 - 68.

King, M., \& Thornhill, C. (2005). Niklas Luhmann Theory of Politics and Law. London: Palgrave.

Laclau, E., \& Mouffe, C. (1987). 'Post-Marxism without Apologies', New Left Review, 166(1), 79-106.

Lefevbre, H. (1992/1974). The Production of Space. Oxford: Blackwell. 


\section{Macrothink}

Luhmann, N. (1982/1981). The Differentiation of Society. New York: Columbia University Press.

Luhmann, N. (1995/1984). Social Systems. Stanford: Stanford University Press.

Luhmann, N. (2004/1993). Law as a Social System. New York: Oxford University Press.

Marx, K., \& Engels, F. (1978/1847). Manifesto of the Communist Party. In: R. Tucker (ed), The Marx - Engels Reader. New York: Norton \& Company, 50-469.

Maturana, H., \& Varela, F. (1979). Autopoiesis and Cognition: The Realization of the Living. London: Reidel.

Maturana, H., \& Varela, F. (1998). The Tree of Knowledge. Boston: Shambhala.

Naveh, S. (1997). In Pursuit of Military Excellence: The Evolution of Operational Theory. London: Routledge.

Ritzer, G. (2007). The McDonaldization of society 5. California: Pine Forge.

Sklair, L. (1995). Sociology of the Global System. London: John Hopkins University Press.

Spivey, N. (1997). The Constructive Metaphor. San Diego: Academic Press.

Toffler, A. (1980). The Third Wave. New-York: Morrow.

Von Bertalanffy, L. (1968). General Systems Theory. New York: George Braziller.

Von Foerster, H. (1974). Cybernetics of Cybernetics. Illinois: University of Illinois

Von Foerster, H. (1981). Observing Systems. California: Intersystems Publications.

Von Foerster, H. (2003). Understanding understanding: Essays on Cybernetics and Cognition. New York: Springer.

Wallerstein, I. (1974). The Modern World System. New York: Academic Press.

Wallerstein, I. (2000). The Essential Wallerstein. New York: The New press.

Weber, M. (2002/1920). The Protestant Ethic and the Spirit of Capitalism. New York: Penguin.

\section{Notes}

Note 1. The constructivist approaches view people as agents of construction, and the knowledge or understanding constructed as being created rather than arriving passively from without. They deal with the effect of human cognizance of knowledge itself, pointing out the role of the observer within the act of observing, and the way in which the subject of the research is to be understood. Two major tenets of constructivism are that knowledge is not a thing received on its own, passively, but rather is created by the knower; and that the construct of knowledge-knowing-understanding is assumed by the observer, and is not a revelation of some ontological truth. For a review of constructivists approaches see for example: Spivey, 1997. 


\section{Macrothink

Note 2. Compare with Lefebvre's description of the shift of Capitalism's influence on social relations: from the sites of production, to the entire social space. (Lefebvre, 1992).

Note 3. It is important to note, that I do not uncouple between capitalism and the emergence of information-age. Obviously, the two are interwoven; and their dialectic relationship is exactly the trait of the mutual-effect of system and environment. Yet, I make here an artificial distinction between them, in the sake of the argument. 